\title{
Bovine mastitis: The diagnostic properties of a PCR-based assay to monitor the Staphylococcus aureus genotype B status of a herd, using bulk tank milk
}

\author{
C. Syring ${ }^{* 1}$ R. Boss,$\dagger^{1}$ M. Reist, $\ddagger$ M. Bodmer, ${ }^{*}$ J. Hummerjohann, $\dagger$ P. Gehrig,, and H. U. Graber $\dagger^{2}$ \\ ${ }^{*}$ Clinic for Ruminants, Department of Clinical Veterinary Medicine, Vetsuisse-Faculty, University of Berne, 3012 Berne, Switzerland \\ †Agroscope Liebefeld-Posieux Research Station ALP, 3003 Berne, Switzerland \\ $\ddagger$ Veterinary Public Health Institute, University of Berne, 3097 Liebefeld, Switzerland \\ §Suisselab AG Zollikofen, 3052 Zollikofen, Switzerland
}

\begin{abstract}
Staphylococcus aureus genotype B (GTB) is a contagious mastitis pathogen in cattle, occurring in up to $87 \%$ of individuals. Because treatment is generally insufficient, culling is often required, leading to large economic loss in the Swiss dairy industry. As the detection of this pathogen in bulk tank milk (BTM) would greatly facilitate its control, a novel real-time quantitative PCR-based assay for BTM has previously been developed and is now being evaluated for its diagnostic properties at the herd level. Herds were initially classified as to their Staph. aureus GTB status by a reference method. Using BTM and herd pools of single-quarter and 4-quarter milk, the herds were then grouped by the novel assay, and the resulting classifications were compared. A total of 54 dairy herds were evaluated. Using the reference method, 21 herds were found to be GTB positive, whereas 33 were found to be negative. Considering the novel assay using both herd pools, all herds were grouped correctly, resulting in maximal diagnostic sensitivities (100\%) and specificities (100\%). For BTM samples, diagnostic sensitivities and specificities were 90 and $100 \%$, respectively. Two herds were false negative in BTM, because cows with clinical signs of mastitis were not milked into the tank. Besides its excellent diagnostic properties, the assay is characterized by its low detection level, high efficiency, and its suitability for automation. Using the novel knowledge and assay, eradication of Staph. aureus GTB from a dairy herd may be considered as a realistic goal.
\end{abstract}

Key words: bulk tank milk, mastitis, polymerase chain reaction, Staphylococcus aureus

\footnotetext{
Received September 23, 2011.

Accepted February 25, 2012.

${ }^{1}$ These authors contributed equally to the present study and should be considered co-first authors.

${ }^{2}$ Corresponding author: hansulrich.graber@alp.admin.ch
}

\section{INTRODUCTION}

Staphylococcus aureus is worldwide one of the most important mastitis pathogens in cattle, involving large economic loss (Halasa et al., 2007; Hogeveen et al., 2011), mainly caused by chronic mastitis. Until now, Staph. aureus has largely been diagnosed and monitored by single-quarter milk samples using an aseptic sample technique and bacteriological culturing. However, this procedure is both laborious and time consuming. In addition, the cyclic shedding of Staph. aureus (Studer et al., 2008) and dead bacteria have a negative effect on the diagnostic sensitivity of conventional bacteriology (Graber et al., 2007). Although sensitivity is increased by repeated sampling, in individual cows it still remains between 41 and 100\% (Sears et al., 1990) or even lower (Studer et al., 2008).

With the development of a ribosomal spacer PCR (RS-PCR) by Fournier et al. (2008), initially 17 Staph. aureus subtypes were isolated from milk samples of mastitic cows in Switzerland. Genotypes B (GTB) and C (GTC) were predominant; the other 15 genotypes were rare (Fournier et al., 2008). The same descriptive study as well as the prospective one of Graber et al. (2009) further revealed that Staph. aureus GTB is udder-associated and contagious, leading to herd problems, whereas Staph. aureus GTC and most of the other genotypes cause single-quarter infections, or are even nonpathogenic. Staphylococcus aureus GTB typically possesses the known enterotoxin genes sea andsed, as well as a polymorphism within the leucotoxin $\mathrm{E}$ gene (lukE, lukEB), as described by Fournier et al. (2008) and Graber et al. (2009). These genetic characteristics have been used to develop a novel analytical approach based on real-time quantitative PCR (qPCR), which is highly sensitive and specific for Staph. aureus GTB (Boss et al., 2011). All other genotypes, as well as the other mastitis pathogens, including Staphylococcus spp., could be unequivocally excluded (Boss et al., 2011). Moreover, the high sensitivity allows the assay to be applied to bulk tank milk (BTM), where the amount of Staph. aureus is often low. The calculated 
detection limit of the novel assay in BTM is 1 Staph. aureus-positive cow among 138 cows (Boss et al., 2011). Bulk tank milk was chosen because bulk milk sampling saves work and expense, and is easy to collect. In addition, BTM reflects the status of the herd, provided the milk of all lactating cows is delivered to the tank. Milk samples lacking this theoretical restriction are pools of milk obtained from each single cow of a herd, as used in the current study: 1) a herd pool of milk taken from all single quarters before milking (QTRpool) or 2) a herd pool of 4-quarter milk samples taken from each cow (COW pool) taken during milking.

The aim of the present field study was to evaluate the diagnostic properties of the GTB assay developed by Boss et al. (2011), at the herd level. The evaluation was performed according to the classical procedure, as recommended by the World Organisation for Animal Health (OIE, 2008). The dairy herds were first classified by the reference method (Fournier et al., 2008) into GTB-positive and GTB-negative herds. The same herds were then grouped by the novel assay of Boss et al. (2011), resulting in a proportion of herds that tested truly positive (= diagnostic sensitivity) and truly negative (= diagnostic specificity) in the assay, respectively. Because the different sample types (BTM, QTRpool, and COWpool) may influence the performance of the assay, the diagnostic properties were calculated for each type separately. In addition, SCC analysis was used to monitor the udder health and milk quality of the herds.

\section{MATERIALS AND METHODS}

\section{Herd Selection}

Fifty-four dairy farms with known GTB status comprising 1,150 cows were sampled between March 2010 and April 2011 in the western half of Switzerland. The GTB status of each herd was assessed using the reference method (RS-PCR) as developed by Fournier et al. (2008), which is described in more detail below.

The farms were typical of Switzerland, with respect to herd size $($ median $=16$ cows $)$. The median herd size of the present study was 18 lactating cows per farm, ranging from 10 to 57 , as very small herds $(<10$ lactating cows) were excluded. The cows were kept in tiestall or freestall housing and milked twice per day. No restriction was placed on breed and farm management.

\section{Milk Sampling}

Each herd was sampled once, either during the morning or evening milking. Cows treated with antibiotics and cows up to $8 \mathrm{~d}$ postpartum were excluded according to legal requirements in Switzerland. For each herd, the following milk samples were collected: 1) single-quarter milk samples of each cow, taken under clean conditions before milking, and pooled for each herd by adding equal volumes $(500 \mu \mathrm{L})$ in the same tube (QTRpool); 2) 4-quarter milk samples of each cow, taken during the milking process by continuously sampling an aliquot of milk from the claw of the cluster using a mechanical Tru-Test milk meter (Tru-Test Inc., Mineral Wells, TX), and pooled for each herd (COWpool); 3) 4-quarter milk samples of each cow containing the stabilizing agent Bronopol, destined for SCC analysis; and 4) BTM, taken after the whole milking process, following the guidelines of the National Mastitis Council (NMC, 1999), disregarding whether the bulk tank contained milk from 1 or multiple milking periods. All samples were transported at $4^{\circ} \mathrm{C}$ to the laboratory, immediately frozen, and stored at $-20^{\circ} \mathrm{C}$ until further use. Samples for SCC analysis were stored at $4^{\circ} \mathrm{C}$ and processed within $1 \mathrm{~d}$.

\section{Reference Method}

The reference method (Fournier et al., 2008) consists of 3 principal steps: 1) the cultivation of Staph. aureus from milk and DNA extraction; 2) the identification of the colonies by PCR; and 3) genotyping by RS-PCR.

Bacteria Cultivation and DNA Extraction. One hundred microliters QTRpool of each farm were plated on CHROMagar Staph. aureus plates (CHROMagar, Paris, France) and incubated at $37^{\circ} \mathrm{C}$ for $24 \mathrm{~h}$. Ten mauve single colonies or as many as possible were then picked and each was inoculated in $100 \mu \mathrm{L}$ of $10 \mathrm{mM}$ Tris/ $\mathrm{HCl}$ and $10 \mathrm{~m} M$ EDTA $(\mathrm{pH}=8.5)$, incubated at $95^{\circ} \mathrm{C}$ for $10 \mathrm{~min}$ for lysis, and immediately placed on ice. These samples were diluted 1:100 in $\mathrm{H}_{2} \mathrm{O}$, so as to be used as a template for PCR with melting curve analysis (mPCR) and for genotyping by the reference method (see below).

nuc Gene $\boldsymbol{m P C R}$. Detection of the thermonuclease gene $(n u c)$ was performed by mPCR-analysis in a Rotor-Gene 6000 real-time thermal cycler (Corbett Life Science, Mortlake, Australia). The PCR reactions were run in a total volume of $20 \mu \mathrm{L}$, containing $1 \times$ Kapa Sybr Fast (Kapa Biosystems Inc., Woburn, MA) and $300 \mathrm{nmol}$ of each primer (Table 1). Then, $2.5 \mu \mathrm{L}$ of template was added to the reaction mix. The PCR steps were as follows: an initial step of $95^{\circ} \mathrm{C}$ for $3 \mathrm{~min}$, 35 cycles of $95^{\circ} \mathrm{C}$ for $3 \mathrm{~s}$ and $60^{\circ} \mathrm{C}$ for $30 \mathrm{~s}$, and a final elongation of $60^{\circ} \mathrm{C}$ for $5 \mathrm{~min}$. Melting of amplicons was performed from 60 to $94^{\circ} \mathrm{C}$, with rising steps of $1^{\circ} \mathrm{C}$ and a $5 \mathrm{~s}$ waiting time at each step. A single melting peak of $80.7 \pm 1.96 \times 0.14^{\circ} \mathrm{C}$ together with an appropriate melting curve of the positive control was regarded as a positive result for Staph. aureus. 
Table 1. Primers and probes used for real-time quantitative PCR (qPCR), ribosomal spacer PCR, and melting curve PCR

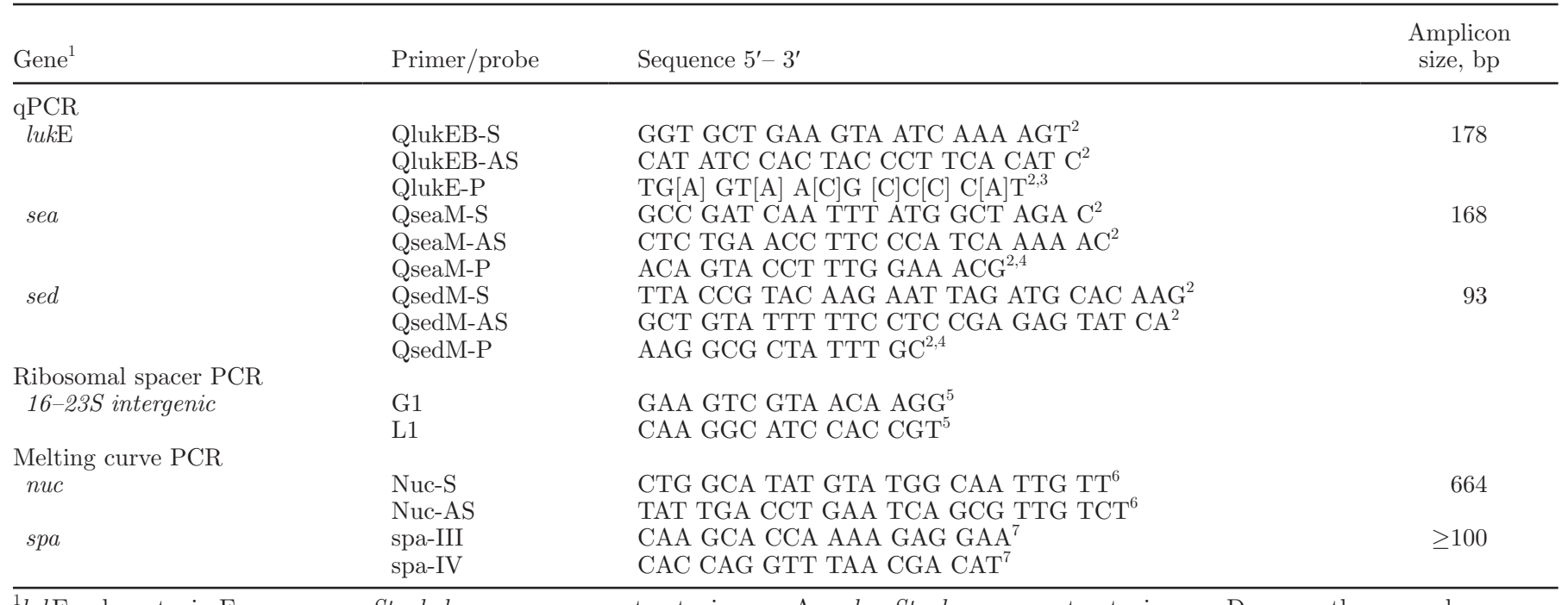

${ }^{1} l u k \mathrm{E}=$ leucotoxin $\mathrm{E}$ gene; sea = Staphylococcus aureus enterotoxin gene $\mathrm{A} ;$ sed $=$ Staph. aureus enterotoxin gene $\mathrm{D} ;$ nuc $=$ thermonuclease gene; spa $=$ Staph. aureus protein A.

${ }^{2}$ Reference: Boss et al. (2011).

${ }^{3}$ Quantitative PCR probe containing locked nucleic acids (within brackets) and labeled with 6-carboxyfluorescein (FAM) at the 5' end and with Black Hole Quencher-1 (BHQ-1) at the $3^{\prime}$ end.

${ }^{4}$ Minor groove binder qPCR probe labeled with 6-carboxyfluorescein (FAM) at the 5 ' end and with a confidential nonfluorescent quencher (NFQ) at the $3^{\prime}$ end.

${ }^{5}$ Reference: Jensen et al. (1993).

${ }^{6}$ Reference: Graber et al. (2007).

${ }^{7}$ Reference: Akineden et al. (2001).

$\boldsymbol{R S}$-PCR. nuc-positive isolates were processed as described by Fournier et al. (2008). In particular, the 16S-23S rRNA intergenic spacer region was amplified by RS-PCR using the primers of Jensen et al. (1993). The amplicons were visualized by the miniaturized electrophoresis system DNA 7500 Chip (Agilent Technologies AG, Basel, Switzerland). Genotypes were defined according to Fournier et al. (2008), improved by calculating the corresponding Mahalanobis distance of informative peak sizes, and by comparing it to those of the reference strains (in-house developed $\mathrm{C} \#$ program). Peaks were considered as informative when the peak height expressed in $\log _{10}$ fluorescent units was higher than $30 \%$ of the $\log _{10}$ mean of the 4 highest peaks. Newly found genotypes were named continuously according to Fournier et al. (2008). A herd was considered to be positive for Staph. aureus GTB if at least 1 colony turned out to be GTB positive by RS-PCR.

\section{Assay for Staph. aureus GTB}

The analytical procedure of Boss et al. (2011) consists of 2 principle steps: 1) the preparation of bacteria from milk and DNA extraction and 2) the detection of the targets (lukEB, sea, and sed).
Bacteria Preparation from Milk and DNA Extraction. In this study, the preparation of bacteria was performed in 2 versions: the original (Boss et al., 2011) as well as a simplified version. The difference is that the latter includes an initial enrichment step allowing several preparation steps to be omitted from the original protocol, thus simplifying the procedure considerably. In particular, staphylococci were first enriched using the staphylococci-specific Chapman medium, containing $75 \mathrm{~g} / \mathrm{L}$ of $\mathrm{NaCl}$ (Merck, Berne, Switzerland), 10 $\mathrm{g} / \mathrm{L}$ of casein peptone (Merck), $10 \mathrm{~g} / \mathrm{L}$ of D-mannitol (Fluka, Buchs, Switzerland), and $1 \mathrm{~g} / \mathrm{L}$ of meet extract (Oxoid AG, Basel, Switzerland). Enrichment was performed using $100 \mu \mathrm{L}$ of prewarmed $\left(37^{\circ} \mathrm{C}\right.$ for $\left.10 \mathrm{~min}\right)$ milk (QTRpool, COWpool, or BTM) was added to 900 $\mu \mathrm{L}$ of Chapman medium and incubated at $37^{\circ} \mathrm{C}$ for 18 $\mathrm{h}$ at $1,000 \mathrm{rpm}$. After incubation, $400 \mu \mathrm{L}$ of culture was added to $1,200 \mu \mathrm{L}$ of a solution containing $180 \mu \mathrm{L}$ of Tris- $\mathrm{HCl}(100 \mathrm{~m} M, \mathrm{pH}=7.8), 300 \mu \mathrm{L}$ of Triton $\mathrm{X}-100$ $2 \%$ (Merck), and $150 \mu \mathrm{L}$ of Lactobacillus casei $(1.5 \times$ $\left.10^{9} \mathrm{cfu}\right)$. After centrifugation $(18,000 \times g$ for $5 \mathrm{~min}$ at $20^{\circ} \mathrm{C}$ ), the supernatant was discarded and the pellet resolved in $150 \mu \mathrm{L}$ of $25 \mathrm{mM}$ Tris- $\mathrm{HCl}$ and $10 \mathrm{mM}$ EDTA $(\mathrm{pH}=7.2)$. The samples were incubated at $95^{\circ} \mathrm{C}$ for 10 min and immediately placed on ice. After this step, the samples were processed as described by Boss et al. 
(2011). The resulting samples of nucleic acids were then used as templates for all qPCR analyses.

$\boldsymbol{q P C R}$. Quantitative PCR including the primers and probes (Table 1) was performed as described by Boss et al. (2011). In brief, the qPCR monoplex reactions for lukEB, sea, sed, and canine distemper virus $\mathrm{N}$ gene $(\mathbf{C D V N})$ were run in a total volume of $25 \mu \mathrm{L}$ containing $1 \times$ Roche LightCycler 480 Probes Master (Roche Diagnostics AG, Rotkreuz, Switzerland), using the appropriate primer and probe concentrations. Finally, 3.5 $\mu \mathrm{L}$ of template was added to the qPCR mix. Pipetting steps were performed by a CAS Robotics liquid handling system (Corbett Robotics Pty. Ltd., Eight Mile Plains, Australia). The qPCR steps were as follows: initial step of $95^{\circ} \mathrm{C}$ for $10 \mathrm{~min}, 45$ cycles of $95^{\circ} \mathrm{C}$ for 15 $\mathrm{s}$, and $60^{\circ} \mathrm{C}$ for $1 \mathrm{~min}$. Quantitative PCR was carried out in a Rotor-Gene 3000 (Corbett Life Science) and was run in duplicate for all genes.

Results were considered positive if both reactions were positive. If only 1 reaction showed a positive result or the difference of the 2 cycle threshold $\left(\mathbf{C}_{\mathbf{T}}\right)$ values was more than 2 cycles, the $\mathrm{qPCR}$ was repeated. A reaction was considered negative for all targets analyzed if amplification resulted in a value $<10$ copies/ reaction. In the case of the enriched samples, values larger than $1.21 \times 10^{4}$ copies of the target gene per assay were considered as positive, whereas lower sample values were considered as negative. This definition was based on a subset of QTRpool data obtained for GTBpositive and -negative herds. For each gene, a standard curve ranging from 10 to $10^{5}$ copies/reaction was used to analyze the data.

Assay Controls. Various controls were included to monitor the whole procedure. To evaluate the preparation of Staph. aureus from milk and culture (enriched samples), 1 sample of sterile raw milk negative for lukEB, sea, sed, and nuc, as well as 1 raw milk sample spiked with $10^{5} \mathrm{cfu}$ of Staph. aureus GTB/mL positive for lukEB, sea, sed, and nuc, were always co-processed with the study samples. If the raw milk sample was positive, or if the spiked sample was not within the adequate range ( \pm twice the expected non-transformed value), all samples of the affected series were prepared again.

For each PCR run, a positive control and a no-template control were included. If the results were negative or positive, respectively, the run was repeated.

To check for qPCR inhibitors eventually present in nucleic acids, the samples were analyzed by an additional qPCR containing CDVN gene amplicons as an internal control, which is detected by CDVN-specific primers and a fluorescent probe (Graber et al., 2007). Negative qPCR results for the target sequences required a positive CDVN qPCR result to exclude inhibitors.

\section{Detection Limit of the GTB Assay Using the Simplified Version of Bacteria Preparation}

Serial dilutions of raw milk spiked with Staph. aureus GTB were prepared with GTB-negative raw milk from $1 \times 10^{5}$ to $1 \mathrm{cfu}$ of Staph. aureus GTB $/ \mathrm{mL}$. The diluted samples were processed by the assay as described above. For all of the target genes, the limit of detection was $10 \mathrm{cfu}$ of Staph. aureus GTB/mL of milk.

\section{SCC Analysis}

Somatic cells of each cow were counted in the 4-quarter milk samples of all individual cows containing the stabilizing agent Bronopol using a Fossomatic 5000 unit (Foss, Hillerød, Denmark) after prewarming the destined milk samples at $37^{\circ} \mathrm{C}$ for $10 \mathrm{~min}$.

\section{Statistical Analysis}

Data are expressed as absolute numbers, percentage, or as $\log _{10}$-transformed values. The diagnostic sensitivity and specificity of the GTB assay, including the corresponding $95 \%$ confidence intervals, were calculated for each type of milk sample separately. The calculations were performed according to the guidelines of OIE (2008), using a $2 \times 2$ contingency table and chi-squared statistics. Classification by the method of Fournier et al. (2008) served as the reference.

For all herds, the SCC values of each cow were $\log _{10}$ transformed $\left(\log _{10} \mathrm{SCC}\right)$ and the corresponding mean $\log _{10}$ SCC values were calculated and compared using the $z$-test. The analysis was performed by the Systat 12 software package (Systat Software Inc., Richmond, CA) or the R 2.7.2. software ( $\mathrm{R}$ Development Core Team, Zurich, Switzerland). A value of $P<0.05$ was considered to be significant.

\section{RESULTS}

\section{Herd Identification by the Reference Method}

Using the reference method, 21 of the 54 herds were found to be GTB positive (Table 2); 33 herds were found to be GTB negative (Table 3), of which 16 were free of Staph. aureus GTB; and 17 herds were found to be free of Staph. aureus.

Overall, the following genotypes and their variants (marked with ' to '"') of Staph. aureus were found (Tables 2 and 3): GTA, GTB, GTB', GTB", GTB"', GTC, GTC", GTF, GTI', GTJ, GTJ", GTL, GTL', GTO', GTR, and GTS. In 2 cases, GTB and GTB variants (GTB" and GTB"') were observed within the same farm. 
Table 2. Herds $(\mathrm{n}=21)$ positive for Staphylococcus aureus genotype B (GTB): SCC, genotypes, and results of the GTB assay using the simplified version of bacteria preparation

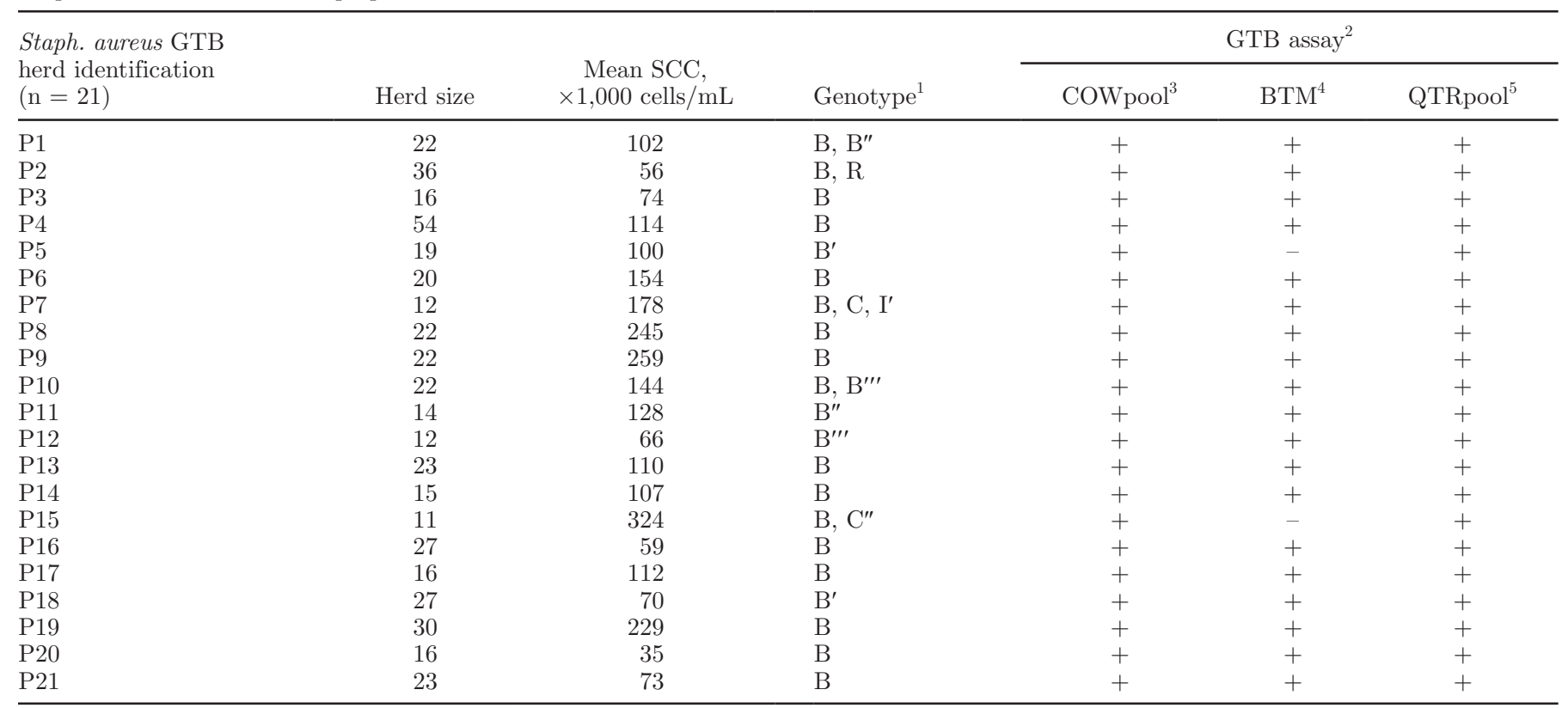

${ }^{1}$ Genotype was determined by the reference method (Fournier et al., 2008).

${ }^{2}+=$ positive for Staph. aureus GTB; $-=$ negative for Staph. aureus GTB.

${ }^{3}$ Four-quarter milk samples of each cow and herd, taken during the milking process and pooled to a single sample.

${ }^{4}$ Bulk tank milk.

${ }^{5}$ Single-quarter milk samples of each cow and herd, taken before milking and pooled to a single sample.

\section{Comparison of Versions of Bacteria Preparation}

Considering the GTB assay, 2 versions of bacteria preparation from milk were initially evaluated: the original version and a simplified version. To achieve this, QTRpool samples from the 54 herds were processed by both versions, followed by identical DNA extraction and $\mathrm{qPCR}$ for the target genes. Both versions generated identical grouping. Because of the excellent congruence of the 2 versions, the study was continued using the simplified version.

\section{Herd Identification by the GTB Assay}

Herd identification by the GTB assay was performed using BTM, COWpool, and QTRpool samples of each herd and the simplified version of bacteria preparation. In the case of the COWpool and QTRpool samples, all 21 GTB-positive herds, initially identified with the reference method, were found to be GTB positive (Table 2 ). For both sample types, the diagnostic sensitivity of the GTB assay was $100 \%(P<0.001)$, with the $95 \%$ confidence interval ranging between 84 and $100 \%$. Regarding the BTM samples, 19 out of 21 herds tested positive, resulting in a diagnostic sensitivity of $90 \%$ $(P<0.001 ; 95 \%$ CI: 70 to $99 \%)$. Two BTM samples were negative because cows with clinical mastitis were excluded from being milked into the bulk tank, as confirmed by the 2 farmers.

Considering the 33 GTB-negative herds, all of them tested negative for this pathogen in all sample types, including COWpool, BTM, and QTRpool (Table 3). The resulting diagnostic specificity was $100 \%$ for all of the sample types $(P<0.001)$, with $95 \%$ confidence interval ranging from 89 to $100 \%$.

\section{SCC}

For each herd, the $\log _{10}$ SCC values present in the 4-quarter milk samples were averaged over all cows; the resulting mean was then back-transformed and is shown in Tables 2 and 3. Comparing the SCC values of all cows of the Staph. aureus GTB-positive herds $(\mathrm{n}=459)$ to those of the non-GTB herds $(\mathrm{n}=691)$, differences in mean $\log _{10} \mathrm{SCC}$ values were found to be highly significant (Figure $1 ; P<0.001$ ). The GTBpositive herds showed an overall mean $\log _{10}$ SCC value and standard deviation of $5.0376 \pm 0.6154 \log _{10}$ (cells/ $\mathrm{mL}$ ), corresponding to a back-transformed mean value of 109,044 cells/mL. The GTB-negative herds showed an overall mean $\log _{10}$ SCC value and standard devia- 
Table 3. Herds $(\mathrm{n}=33)$ negative for Staphylococcus aureus genotype B (GTB), consisting of 16 herds free of Staph. aureus GTB and 17 herds free of Staph. aureus: SCC, genotypes, and results of the GTB assay using the simplified version of bacteria preparation

\begin{tabular}{|c|c|c|c|c|c|c|}
\hline Herd identification & Herd size & $\begin{array}{c}\text { Mean SCC, } \\
\times 1,000 \text { cells } / \mathrm{mL}\end{array}$ & Genotype $^{1}$ & \multicolumn{3}{|c|}{ 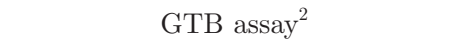 } \\
\hline $\mathrm{C} 1$ & 10 & 65 & $\mathrm{~S}$ & - & - & - \\
\hline $\mathrm{C} 2$ & 14 & 52 & $\mathrm{C}$ & - & - & - \\
\hline C3 & 24 & 61 & $\mathrm{~F}$ & - & - & - \\
\hline $\mathrm{C} 4$ & 12 & 75 & $\mathrm{C}$ & - & - & - \\
\hline $\mathrm{C} 7$ & 15 & 82 & $\mathrm{C}$ & - & - & - \\
\hline $\mathrm{C} 8$ & 13 & 71 & C, L & - & - & - \\
\hline C9 & 21 & 71 & $\mathrm{C}$ & - & - & - \\
\hline C10 & 12 & 87 & $\mathrm{C}$ & - & - & - \\
\hline $\mathrm{C} 11$ & 22 & 65 & $\mathrm{C}$ & - & - & - \\
\hline $\mathrm{C} 12$ & 15 & 185 & C. S & - & - & - \\
\hline $\mathrm{C} 13$ & 11 & 91 & $\mathrm{~L}^{\prime}$ & - & - & - \\
\hline \multicolumn{7}{|c|}{ Herds free of Staph. aureus $(\mathrm{n}=17)$} \\
\hline $\mathrm{C} 18$ & 19 & 52 & None & - & - & - \\
\hline C19 & 38 & 64 & None & - & - & - \\
\hline $\mathrm{C} 20$ & 18 & 34 & None & - & - & - \\
\hline $\mathrm{C} 21$ & 18 & 50 & None & - & - & - \\
\hline $\mathrm{C} 22$ & 13 & 120 & None & - & - & - \\
\hline $\mathrm{C} 23$ & 14 & 53 & None & - & - & - \\
\hline $\mathrm{C} 24$ & 38 & 38 & None & - & - & - \\
\hline $\mathrm{C} 25$ & 13 & 43 & None & - & - & - \\
\hline $\mathrm{C} 26$ & 13 & 28 & None & - & - & - \\
\hline $\mathrm{C} 27$ & 22 & 47 & None & - & - & - \\
\hline $\mathrm{C} 28$ & 57 & 83 & None & - & - & - \\
\hline $\mathrm{C} 29$ & 14 & 27 & None & - & - & - \\
\hline C30 & 13 & 48 & None & - & - & - \\
\hline
\end{tabular}

${ }^{1}$ Genotype was determined by the reference method (Fournier et al., 2008).

${ }^{2}+=$ positive for Staph. aureus GTB; - = negative for Staph. aureus GTB.

${ }^{3}$ Four-quarter milk samples of each cow and herd, taken during milking process and pooled to a single sample.

${ }^{4}$ Bulk tank milk.

${ }^{5}$ Single-quarter milk samples of each cow and herd, taken before milking and pooled to a single sample.

tion of $4.8026 \pm 0.5091 \log _{10}($ cells $/ \mathrm{mL})$, with a backtransformed mean value of 63,475 cells $/ \mathrm{mL}$.

\section{DISCUSSION}

The present study demonstrates that the assay developed by Boss et al. (2011) allows the GTB status of a herd to be efficiently and reliably determined when BTM, COWpool, or QTRpool samples are used, findings which may be of particular importance to the dairy industry. For Switzerland, Staph. aureus GTB is nothing else but the contagious subtype of Staph. aureus, so that infected herds can be sanitized by the well-known procedures (e.g., Kirchhofer et al., 2011).

\section{Relevance of the Novel Assay for Staph. aureus GTB}

Staphylococcus aureus GTB causes considerable financial loss in dairy farming. Typically, half of the cows in any affected herd will be infected with this pathogen (Fournier et al., 2008; Graber et al., 2009). Moreover, treatment success is generally low (Gruet et al., 2001; Sears and McCarthy, 2003) and this leads to a high culling and replacing rate of GTB-positive cows. The contagious nature of Staph. aureus GTB is in clear contrast to the other genotypes, as these typically either only infect single cows or lack pathogenicity altogether (Fournier et al., 2008; Graber et al., 2009). Consequently, these other genotypes are of very limited importance as a contagious agent causing mastitis. The 


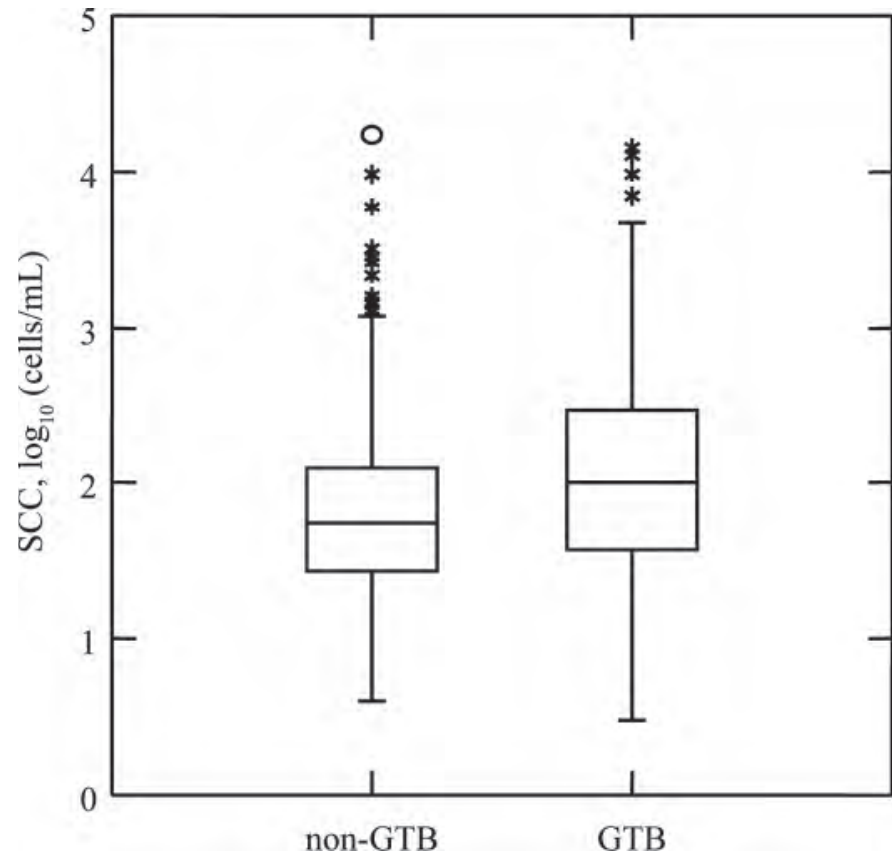

Figure 1. Overall SCC between herds positive for Staphylococcus aureus genotype $\mathrm{B}$ (GTB; $\mathrm{n}=459$ cows) and negative for GTB (non$\mathrm{GTB} ; \mathrm{n}=691$ cows), respectively. The mean $\log _{10} \mathrm{SCC}$ values differed between the GTB and non-GTB herds $(P<0.001)$. ${ }^{*}=$ outlier; $O=$ far outlier.

availability of the novel highly efficient, specific, and sensitive assay for monitoring the GTB status at the herd and cow level brings eradication of Staph. aureus GTB within reach. As far as the authors are aware, this has never been a realistic goal before, as the conventional diagnostic methods available so far have not been sensitive and specific enough(Sears et al., 1990; Studer et al., 2008; Olde Riekerink, 2010). These features have rendered sanitation and control of infected herds inefficient or impossible, and have resulted in high costs.

Implementation of an eradication program for Staph. aureus GTB in Switzerland is expected to considerably decrease the costs to the Swiss dairy industry caused by decreased milk quality, treatment, and cow replacements. In addition, regular control of dairy herds for Staph. aureus GTB using BTM or COWpool samples would be advantageous due to the high sensitivity of the novel assay, which allows each newly infected cow to be detected early so that the spread of the disease within a herd is minimal. A further advantage of the novel GTB assay is the fact that aseptic sampling at the cow level is no longer necessary for this pathogen. Sampling under just clean conditions is sufficient, a property that greatly simplifies the detection of GTB status in individual cows, the key prerequisite for successful herd sanitation. A first move toward realizing the eradication strategy in Switzerland will now be made, as the
GTB analytical procedure of Boss et al. (2011) will soon be implemented in a routine laboratory.

Until now, IMI caused by Staph. aureus GTB has only been confirmed in Switzerland. To our best knowledge, similar findings have never been described in other countries. From collaborations, we know, however, that Staph. aureus GTB is also present in dairy herds of other European regions, suggesting that this pathogen is not limited to Switzerland, and that the Swiss findings, therefore, may also be valid for other regions. To confirm this hypothesis, a study has been started to genotype bovine strains of Staph. aureus from various European areas.

\section{Methodological Aspects}

The protocol of the novel GTB assay of Boss et al. (2011) can be divided into a first step dealing with preparation of bacteria from milk and a second step addressing the target detection. Concerning bacteria preparation, 2 versions were applied in the present study: the original version, as described by Boss et al. (2011), and a simplified version. Although the latter one includes an additional enrichment step, by culturing the milk staphylococci in a selective medium overnight, various steps of the analytical procedure could subsequently be omitted, so that manual work, several incubation steps, and reagents could be reduced, or even left out. These changes considerably shorten the analytical process itself and require only minimal additional planning (incubation overnight). In addition, they result in a higher sample throughput and lower costs, which are, together with robustness and suitability for automation, important properties of an analytical procedure to be used for routine applications in the future. A disadvantage of the simplified version of bacteria preparation is its dependency on milk being free from antibiotics or additives (e.g., Bronopol), as these inhibit bacterial growth during the enrichment step, a limitation not existing for the original protocol described by Boss et al. (2011). In addition, the simplified version of bacteria preparation only provides qualitative, but not quantitative, information. The main application of the simplified version, however, is to detect or exclude GTB-positive herds or individual cows using the appropriate samples. Therefore, this qualitative information is adequate. Moreover, this information is also sufficient for screening and monitoring whole herds or individual cows during a GTB eradication program.

The original version of bacteria preparation works with live and dead bacteria, whereas the simplified version requires live cells. These differences, however, seem of limited relevance because both versions grouped the herds in the same way. 
Considering the GTB assay, correct discrimination between GTB-positive and GTB-negative herds was observed when either QTRpool or COWpool samples were used. In view of the actual sampling process, however, COWpool samples are much more convenient than QTRpool samples, as they require less manual work and material. Based on the study of Sears et al. (1991) using single-quarter milk, however, a pool of milk taken before milking (QTRpool) is expected to yield higher diagnostic sensitivity and lower diagnostic specificity than a pool of milk collected during milking (COWpool), as the amount of bacteria shed into the milk is considerably higher before milking than at the end. The obtained data, however, do not support these theoretical considerations, as both sample types generated identical results. In the case of the BTM samples, the diagnostic sensitivity was $90 \%$. This result is not surprising, as, in contrast to the COWpool and QTRpool samples, the BTM samples only represent cows that are actually milked into the bulk tank. In fact, 2 herds had positive results for GTB in the QTRpool and COWpool samples, but not for the BTM samples. As confirmed by both farmers, cows with poor udder health were excluded from being milked into the tank. These findings imply that correct herd identification by BTM requires additional milk samples of all cows, which are excluded from being milked into the tank. These samples may be pooled and analyzed separately.

In the present study, 10 genotypes of Staph. aureus and 8 variants were isolated from milk. New variants were classified according to Fournier et al. (2008) and include GTB', GTB", GTB"', GTC", GTJ", GTL', and GTO' and demonstrate the high genetic variability of Staph. aureus in Swiss dairy herds. Interestingly, we found, for the first time, variants of GTB (GTB', GTB", and GTB"'). They differ from the original GTB genotype in their lack of, or only the weak presence of a single band, indicating 1 or more mutations within 1 or both primer binding sites.

\section{SCC Analyses}

Somatic cell count is an important indicator for udder health and milk quality (Schukken et al., 2003). Increased SCC values may result either from IMI or from noninfectious injury of the udder. It is, therefore, not surprising that the GTB-positive herds included in the present study showed increased SCC values. Indeed, the mean SCC value of GTB-positive herds was approximately twice as high (nontransformed values) as the one of the non-GTB herds $(P<0.001)$, showing that udder health and milk quality had actually decreased in GTB-positive herds. These results are in close agreement with our former findings (Fournier et al., 2008; Graber et al., 2009; Michel et al., 2011), which demonstrated a remarkably close correlation between SCC and the GTB status of a herd.

\section{CONCLUSIONS}

The field evaluation of a novel qPCR-based assay to detect Staph. aureus GTB in milk resulted in very high diagnostic sensitivities and specificities in BTM, COWpool, and QTRpool samples and, thus, was found suitable to monitor the GTB status of a herd. The analytical procedure is highly efficient and automatable and is, therefore, appropriate for routine applications.

\section{ACKNOWLEDGMENTS}

The study was supported by a grant of the Swiss Federal Veterinary Office FVO (Berne, Switzerland) and the Swiss dairy industry (Fromarte, Berne, Switzerland; Schweizer Milchproduzenten SMP Genossenschaft, Berne, Switzerland; Suisselab, Zollikofen, Switzerland; and TSM Treuhand GmbH, Berne, Switzerland). We thank Swissherdbook (Zollikofen, Switzerland) for the logistic support and Kirsten Hansen (Clinic for Ruminants, Department of Clinical Veterinary Medicine, Vetsuisse-Faculty, University of Berne, Switzerland) for her assistance in sample collection.

\section{REFERENCES}

Akineden, Ö., C. Annemüller, A. A. Hassan, C. Lämmler, W. Wolter, and M. Zschöck. 2001. Toxin genes and other characteristics of Staphylococcus aureus isolates from milk of cows with mastitis. Clin. Diagn. Lab. Immunol. 8:959-964.

Boss, R., J. Naskova, A. Steiner, and H. U. Graber. 2011. Mastitis diagnostics: Quantitative PCR for Staphylococcus aureus genotype B in bulk tank milk. J. Dairy Sci. 94:128-137.

Fournier, C., P. Kuhnert, J. Frey, R. Miserez, M. Kirchhofer, T. Kaufmann, A. Steiner, and H. U. Graber. 2008. Bovine Staphylococcus aureus: Association of virulence genes, genotypes and clinical outcome. Res. Vet. Sci. 85:439-448.

Graber, H. U., M. G. Casey, J. Naskova, A. Steiner, and W. Schaeren. 2007. Development of a highly sensitive and specific assay to detect Staphylococcus aureus in bovine mastitic milk. J. Dairy Sci. 90:4661-4669.

Graber, H. U., J. Naskova, E. Studer, T. Kaufmann, M. Kirchhofer, M Brechbühl, W. Schaeren, A. Steiner, and C. Fournier. 2009. Mastitis-related subtypes of bovine Staphylococcus aureus are characterized by different clinical properties. J. Dairy Sci. 92:1442-1451.

Gruet, P., P. Maincent, X. Berthelot, and V. Kaltsatos. 2001. Bovine mastitis and intramammary drug delivery: Review and perspectives. Adv. Drug Deliv. Rev. 50:245-259.

Halasa, T., K. Huijps, O. Østerås, and H. Hogeveen. 2007. Economic effects of bovine mastitis and mastitis management: A review. Vet. Q. 29:18-31.

Hogeveen, H., K. Huijps, and T. J. G. M. Lam. 2011. Economic aspects of mastitis: New developments. N. Z. Vet. J. 59:16-23.

Jensen, M. A., J. A. Webster, and N. Straus. 1993. Rapid identification of bacteria on the basis of polymerase chain reaction-amplified ribosomal DNA spacer polymorphisms. Appl. Environ. Microbiol. 59:945-952. 
Kirchhofer, M., T. Kaufmann, M. Guélat-Brechbühl, A. Michel, C. Syring, and M. Bodmer. 2011. Systematic sanitation of dairy herds with mastitis caused by Staphylococcus aureus. Schweiz. Arch. Tierheilkd. 153:361-368.

Michel, A., C. Syring, A. Steiner, and H. U. Graber. 2011. Intramammary infections with the contagious Staphylococcus aureus genotype B in Swiss dairy cows are associated with low prevalence of coagulase-negative staphylococci and Streptococcus spp. Vet. J. 188:313-317.

NMC (National Mastitis Council). 1999. Laboratory Handbook on Bovine Mastitis. Rev. ed. National Mastitis Council Inc., Madison, WI.

OIE (World Organisation for Animal Health). 2008. Principles of validation of diagnostic assays for infectious diseases (Chapter 1.1.4) and Validation and quality control of polymerase chain reaction methods used for the diagnosis of infectious diseases (Chapter 1.1.5) in Manual of Diagnostic Tests and Vaccines for Terrestrial Animals. 6th ed. OIE, Paris, France.

Olde Riekerink, R. G. M., H. W. Barkema, D. T. Scholl, D. E. Poole, and D. F. Kelton. 2010. Management practices associated with the bulk-milk prevalence of Staphylococcus aureus in Canadian dairy farms. Prev. Vet. Med. 97:20-28.

Schukken, Y. H., D. J. Wilson, F. Welcome, L. Garrison-Tikofsky, and R. N. Gonzalez. 2003. Monitoring udder health and milk quality using somatic cell counts. Vet. Res. 34:579-596.

Sears, P. M., and K. K. McCarthy. 2003. Management and treatment of staphylococcal mastitis. Vet. Clin. North Am. Food Anim. Pract. 19:171-185.

Sears, P. M., B. S. Smith, P. B. English, P. S. Herer, and R. N. Gonzalez. 1990. Shedding pattern of Staphylococcus aureus from bovine intramammary infections. J. Dairy Sci. 73:2785-2789.

Sears, P. M., D. J. Wilson, R. N. Gonzalez, and D. D. Hancock. 1991. Microbiological results from milk samples obtained premilking and postmilking for the diagnosis of bovine intramammary infections. J. Dairy Sci. 74:4183-4188.

Studer, E., W. Schaeren, J. Naskova, H. Pfaeffli, T. Kaufmann, M. Kirchhofer, and A. Steiner. 2008. A longitudinal field study to evaluate the diagnostic properties of a quantitative real-time polymerase chain reaction-based assay to detect Staphylococcus aureus in milk. J. Dairy Sci. 91:1893-1902. 